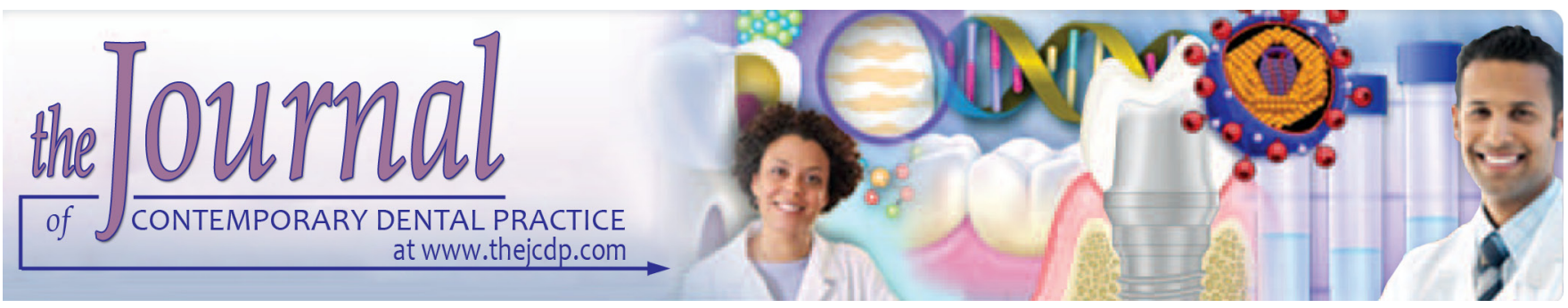

\title{
An Analysis of the Stress Induced in the Periodontal Ligament during Extrusion and Rotation Movements: A Finite Element Method Linear Study Part I
}

${ }^{1} \mathrm{M}$ Hemanth, ${ }^{2} \mathrm{HP}$ Raghuveer, ${ }^{3} \mathrm{MS}$ Rani, ${ }^{4}$ Chathura Hegde, ${ }^{5}$ Karthik J Kabbur, ${ }^{6} \mathrm{~B}$ Vedavathi, ${ }^{7} \mathrm{D}$ Chaithra

\begin{abstract}
Background: Orthodontic tooth movement occurs due to various biomechanical changes in the periodontium. Forces within the optimal range yield maximum tooth movement with minimum deleterious effects. Among various types of tooth movements, extrusion and rotational movements are seen to be associated with the least amount of root resorption and have not been studied in detail. Therefore in this study, the stress patterns in the periodontal ligament (PDL) were evaluated with extrusion and rotational movements using the finite element method FEM.
\end{abstract}

Materials and methods: A three-dimensional (3D) FEM model of the maxillary incisors was generated using SOLIDWORKS modeling software. Stresses in the PDL were evaluated with extrusive and rotational movements by a 3D FEM using ANSYS software with linear material properties.

Results: It was observed that with the application of extrusive load, the tensile stresses were seen at the apex, whereas the compressive stress was distributed at the cervical margin. With the application of rotational movements, maximum compressive stress was distributed at the apex and cervical third, whereas the tensile stress was distributed on cervical third of the PDL on the lingual surface.

\footnotetext{
${ }^{1,4,5,7}$ Department of Orthodontics and Dentofacial Orthopedics Dayananda Sagar College of Dental Science, Bengaluru Karnataka, India

${ }^{2}$ Department of Oral and Maxillofacial Surgery, Dayananda Sagar College of Dental Science, Bengaluru, Karnataka, India

${ }^{3}$ Department of Orthodontics and Dentofacial Orthopedics VS Dental College and Hospital, Bengaluru, Karnataka, India

${ }^{6}$ Department of Conservative and Endodontics, Dayananda Sagar College of Dental Science, Bengaluru, Karnataka, India

Corresponding Author: M Hemanth, Professor and Head Department of Orthodontics and Dentofacial Orthopedics Dayananda Sagar College of Dental Science, Bengaluru Karnataka, India, Phone: 09845459666, e-mail: drhemanth@ yahoo.com
}

Conclusion: For extrusive movements, stress values over the periodontal ligament was within the range of optimal stress value as proposed by Lee, with a given force system by Profitt as optimum forces for orthodontic tooth movement using linear properties. During rotation there are stresses concentrated at the apex, hence due to the concentration of the compressive forces at the apex a clinician must avoid placing heavy stresses during tooth movement.

Keywords: Extrusion, Finite element method, Linear analysis, Optimum force, Rotation.

How to cite this article: Hemanth M, Raghuveer HP, Rani MS, Hegde C, Kabbur KJ, Vedavathi B, Chaithra D. An Analysis of the Stress Induced in the Periodontal Ligament during Extrusion and Rotation Movements: A Finite Element Method Linear Study Part I. J Contemp Dent Pract 2015;16(9):740-743.

Source of support: Nil

Conflict of interest: None

\section{INTRODUCTION}

The quantification of the force that would bring about maximum tooth movement with least tissue damage during orthodontic tooth movement poses a challenge to the clinician. The force applied to the tooth generates stress in the periodontal ligament (PDL) which in turn is transmitted to the alveolus which subsequently remodels bringing about tooth movement. Hence, tooth movement is primarily mediated by the PDL. ${ }^{1}$ Several animal, laboratory and clinical studies have attempted to relate the forces applied to the stress generated in the PDL with the quality and speed of the tooth movement. ${ }^{2-4}$ Among all the methods, the finite element analysis (FEM) is one of the best available methods for studying the magnitude and pattern of stress because of its uniqueness to handle complex shapes and nonhomogenous nature of materials. ${ }^{5}$

Since the distribution of stress in the PDL varies with different types of tooth movement, it is necessary 
to specify the type of tooth movement in discussing optimum force levels for orthodontic purposes.

Among all types of tooth movement, extrusion and rotation causes least amount of root resorption. However, these movements are routinely used in a clinical scenarios. The optimal force range for extrusion and rotation movements and their relation with the range of optimal stress have not been studied much in the literature. Hence, the purpose of this study is to evaluate the magnitude and distribution of stress in the PDL on application of extrusion and rotation forces on a 3 dimensional FEM model of maxillary central incisor.

\section{AIMS AND OBJECTIVES}

- To evaluate the distribution of stress pattern in PDL on application of orthodontic load (viz extrusive force and rotational force) on maxillary central incisors with a three-dimensional (3D) finite element analysis using linear properties.

- To determine the optimal forces for extrusive and rotational movements.

\section{MATERIALS AND METHODS}

In this study, a 3D finite element model of a maxillary central incisor was created and used to calculate the stress in the periodontal ligament by a 3D finite element method (FEM) and compare these stresses in the periodontal ligament using linear analysis.

\section{Computational Facilities used for the Study}

Hardware: A PC workstation having an Intel Core DUO processor with 8 GB RAM, 500 GB secondary storage and graphic accelerator were used for the study.

Software: The Design program used was SOLIDWORKS release 2012; 3D modeling software and the finite element analysis (FEA) program used was ANSYS workbench.

The finite element model consists of geometric model, material properties of the model, loading configuration. In this study, the analytical model incorporating maxillary central incisor along with PDL, cortical and compact bone were developed according to dimensions and morphology found in a standard textbook of dental anatomy, physiology and occlusion by Wheeler's. ${ }^{6}$ Periodontal ligament was simulated as a $0.2 \mathrm{~mm}$ thick layer around the model of the tooth and cortical bone at $0.5 \mathrm{~mm}$ thick $^{7}$ (Fig. 1A). The finite element model approximately consisted of 1,48,097 tetrahedral elements 2,39,666 Nodes and $3^{\circ}$ of freedom (Figs 1B and C).

Each structure was then assigned a specific material property. The material properties used in this study have been taken from finite element studies previously conducted. ${ }^{8}$ These material properties were defined as linear and isotropic for linear analysis (Table 1).

For extrusion the load was applied parallel to the long axis of tooth away from the apex and for rotation two equal and opposite forces (couple) was applied at the cervical margin of $\operatorname{tooth}^{5}$ (Table 2).

\section{RESULTS}

The forces were applied on the maxillary central incisor for extrusive and rotational movements and the resulting equations were solved with linear properties by ANSYS workbench software. The stress patterns produced in PDL were also analyzed and calculated in terms of principal stresses. The maximum value of the first principal stress and the minimum value of the third principal stress were recorded. All the minimum principal stresses were considered as compressive stress and were assigned a negative value and all the maximum principal stresses were considered as tensile stress and were assigned a positive value.

When $0.6 \mathrm{~N}$ of extrusive forces were applied along the long axis of the tooth it produced compressive stresses as high as $0.812 \times 10^{-3} \mathrm{~N} / \mathrm{mm}^{2}$ and the tensile were as high as $0.04198 \mathrm{~N} / \mathrm{mm}^{2}$ (Fig. 2). The stresses were beyond the optimal range as given by Lee $\left(0.015-0.026 \mathrm{~N} / \mathrm{mm}^{2}\right)$, hence the force was decreased to $0.35 \mathrm{~N}$ through iteration. When $0.35 \mathrm{~N}$ of extrusive forces were applied along the long axis of the tooth it produced compressive stresses as high as $-0.474 \times 10^{-3} \mathrm{~N} / \mathrm{mm}^{2}$ and the tensile stresses as high as $0.0244 \mathrm{~N} / \mathrm{mm}^{2}$ which were with in the range (Fig. 3).

While rotatory forces (couple) of two equal and opposing forces of $0.35 \mathrm{~N}$ using linear properties were applied at the cervical margin of the crown it produced compressive stresses of $-0.0022 \mathrm{~N} / \mathrm{mm}^{2}$ and tensile stress $0.014 \mathrm{~N} / \mathrm{mm}^{2}$ at the apex of the PDL (Fig. 4) which were

Table 1: Linear material properties

\begin{tabular}{lll}
\hline Material & $\begin{array}{l}\text { Young's Modulus } \\
\left(\mathrm{N} / \mathrm{mm}^{2}\right)\end{array}$ & Poisson's ratio \\
\hline Enamel & $8.41 \times 104$ & 0.33 \\
Periodontal ligament & $6.90 \times 0-1$ & 0.45 \\
Cancellous bone & $1.37 \times 104$ & 0.3 \\
Cortical bone & $3.45 \times 105$ & 0.3 \\
\hline
\end{tabular}

Table 2: Loading configuration

\begin{tabular}{|c|c|c|}
\hline $\begin{array}{l}\text { Type of tooth } \\
\text { movement }\end{array}$ & $\begin{array}{l}\text { Magnitude of } \\
\text { force (in newtons) }\end{array}$ & Direction \\
\hline Extrusion & $\begin{array}{l}0.6 \mathrm{~N} \\
0.35 \mathrm{~N}\end{array}$ & $\begin{array}{l}\text { Vertical forces applied } \\
\text { along the long axis of the } \\
\text { tooth away from the apex }\end{array}$ \\
\hline Rotation & $\begin{array}{l}0.35 \mathrm{~N} \\
0.8 \mathrm{~N}\end{array}$ & $\begin{array}{l}\text { Two forces of equal } \\
\text { magnitude and opposite } \\
\text { direction (couple) }\end{array}$ \\
\hline
\end{tabular}


below the optimal stress range. Hence, the force levels were increased to $0.8 \mathrm{~N}$ through iterations. When a couple of $0.8 \mathrm{~N}$ were applied at the cervical margin of the crown
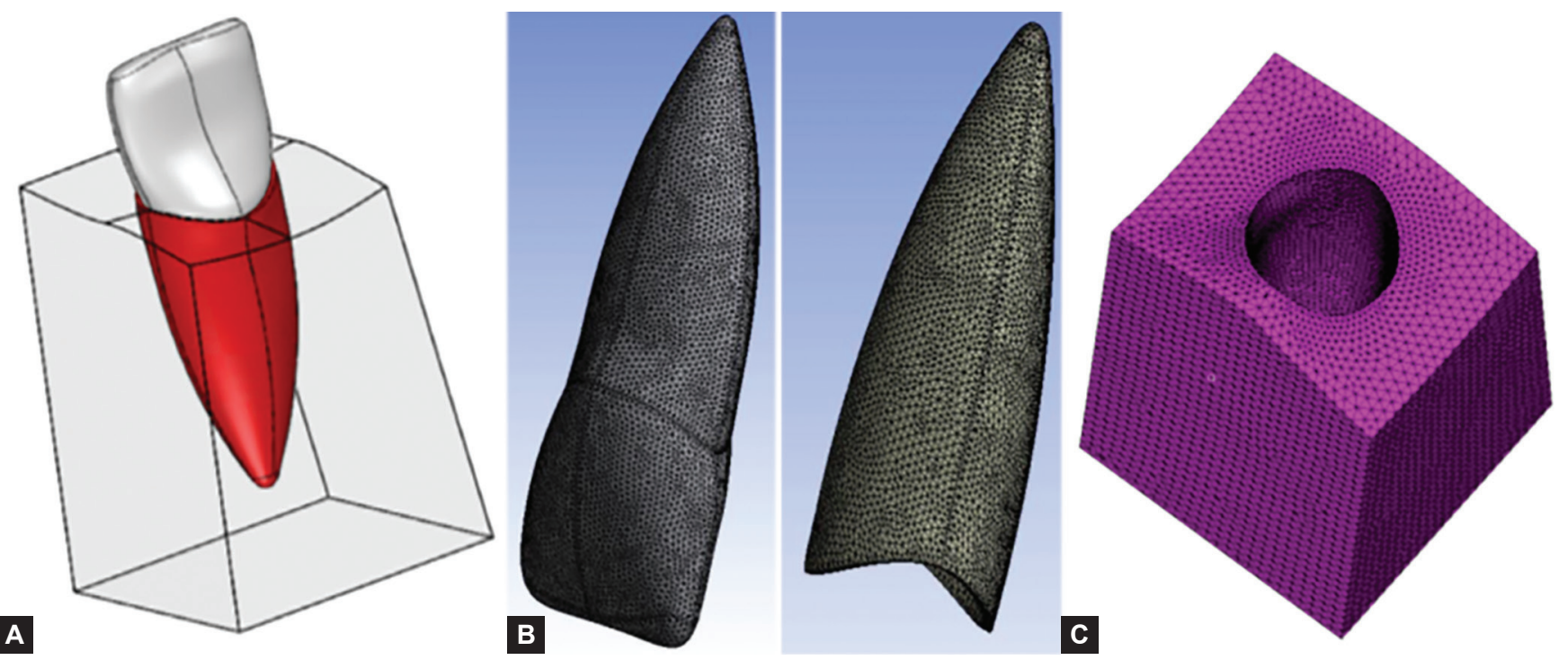

Figs $1 \mathrm{~A}$ to $\mathrm{C}$ : (A) Geometric model of maxillary central incisor and supporting structures in SOLIDWORKS software and ( $B$ and $C$ ) Model showing elements and nodes distribution (1,48,097 elements and 2,39,666 nodes)

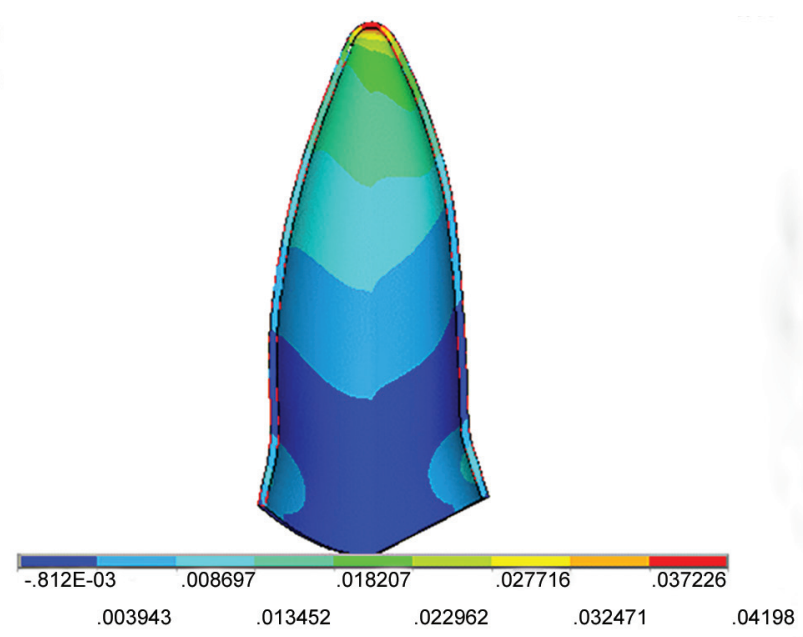

Fig. 2: Distribution of principle stress in PDL on application of extrusive force of $0.6 \mathrm{~N}$ using linear properties
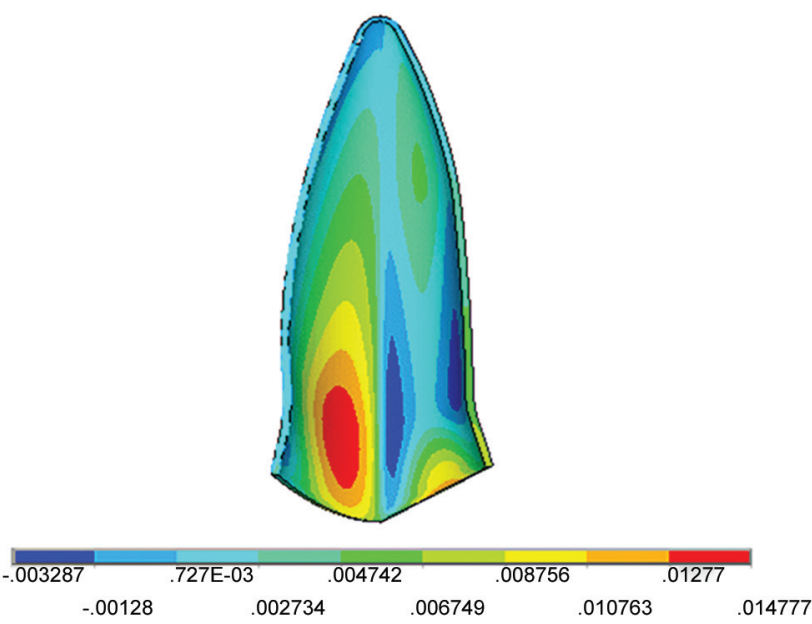

Fig. 4: Distribution of principle stress in PDL on application of rotational force of $0.35 \mathrm{~N}$ using linear properties

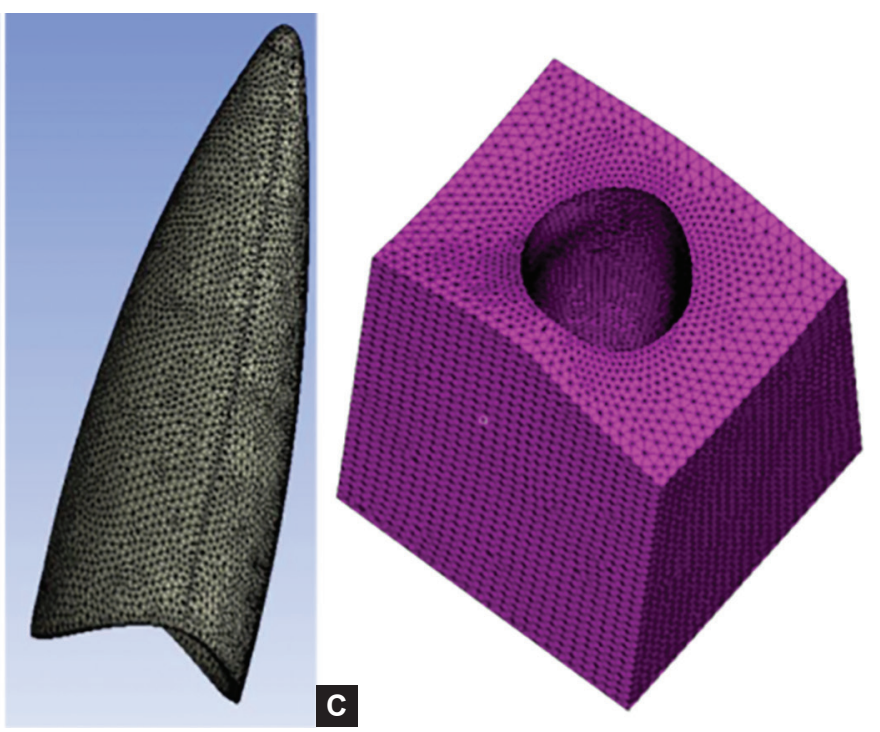

it produced it produced a compressive stress of $-0.017 \mathrm{~N} /$ $\mathrm{mm}^{2}$ and a tensile stress of $0.020 \mathrm{~N} / \mathrm{mm}^{2}$ (Fig. 5) which were within the optimal stress levels stated by Lee.
Fig. 3: Distribution of principle stress in PDL on application of extrusive force of $0.35 \mathrm{~N}$ using linear properties
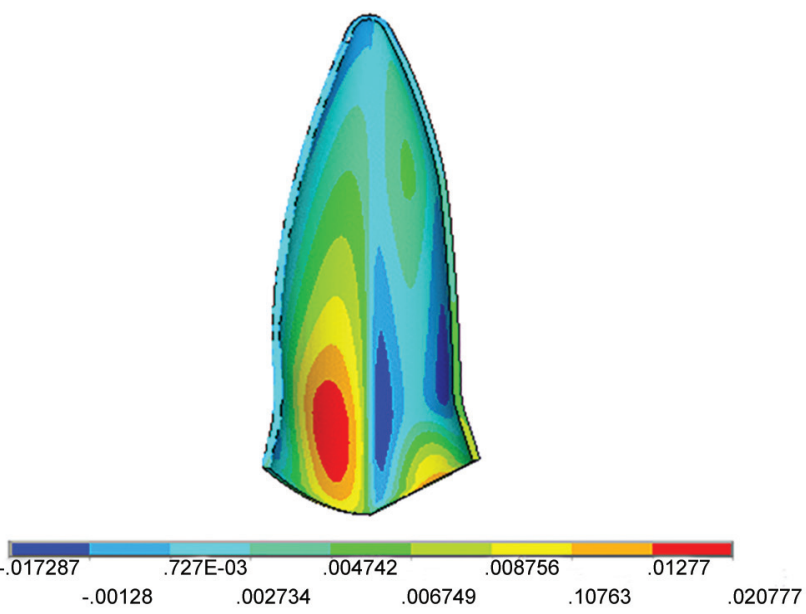

Fig. 5: Distribution of principle stress in PDL on application of rotational force of $0.8 \mathrm{~N}$ using linear properties 


\section{DISCUSSION}

The present study evaluated the pattern, magnitude of stresses and quantified the optimal stresses in the PDL for extrusion and rotational movement on a maxillary central incisor model using linear material properties through FEM.

The pattern of stress distribution for extrusion is as follows: the compressive stress is seen predominantly distributed at the cervical third of the PDL, the tensile stress is distributed at the apex of the PDL. The similar pattern of stress distribution is seen in a study by Rudolph et al. ${ }^{5}$

The maximum tensile stress at the apex was found to be $0.04198 \mathrm{~N} / \mathrm{mm}^{2}$ for a loading of $0.6 \mathrm{~N}$. The stress value was beyond the optimal range as given by Lee 9 $\left(0.015-0.026 \mathrm{~N} / \mathrm{mm}^{2}\right)$, hence the force levels are reduced through iterations to $0.35 \mathrm{~N}$, in order to obtain stresses with in the optimal range. With $0.35 \mathrm{~N}$, the stresses obtained was $0.0244 \mathrm{~N} / \mathrm{mm}^{2}$. The magnitude of stresses is not coinciding with the study done by Rudolph et al, ${ }^{5}$ however, they evaluated for von Mises stress in their study. The force applied was also with in the range of optimal force value as suggested by Proffit ${ }^{1}$ (extrusion 35-60 gm).

The pattern of stress distribution for rotational force are the compressive stress is distributed at the cervical third and apex of the PDL on the labial and lingual surface respectively. The tensile stress is distributed at the cervical third of the PDL on lingual surface. The similar pattern of stress distribution is seen in a study by Rudolph et al. ${ }^{5}$

The magnitude of stress with the application of $0.35 \mathrm{~N}$ couple was $0.014 \mathrm{~N} / \mathrm{mm}^{2}$ which was less than the optimal stress range as suggested by Lee $^{9}\left(0.015-0.026 \mathrm{~N} / \mathrm{mm}^{2}\right)$ through iteration the force levels were increased to $0.8 \mathrm{~N}$ in which the stresses obtained were $0.020 \mathrm{~N} / \mathrm{mm}^{2}$. However, the forces was not within the optimal range as given by Proffit ${ }^{1}$ ( rotation 35-60 gm). The magnitude of stresses coincided with a study done by Kamble et al. ${ }^{10}$

The pattern of stress distribution could be attributed to anatomical variation of the root surface, i.e. the bulge and depressions on the surface of root. ${ }^{11}$ This study shows that extrusive forces produces tensile stress at the apex and compressive stress at the cervical third of the PDL and rotation forces produces compressive stress at the root apex and tensile stress at the cervical third.

\section{CONCLUSION}

For the stresses in the PDL to be in the optimum limit as suggested by Lee the extrusive force load should not exceed beyond $0.35 \mathrm{~N}$ which is within the optimal force limit as suggested by Proffit for extrusion, i.e. (35-60 gm) and that for rotation the load must not exceed beyond $0.8 \mathrm{~N}$ as loads in excess of these would be detrimental to the health of the supporting tissues.
Finite element method is an approximation study whose accuracy is dependent on modeling the structure and material characterization as close as possible to the actual. Periodontal ligament is nonlinear and anisotropic in nature. The viscous nature of the periodontal ligament comes from the tissue fluid and elastic behaviour from the fibers. The anisotropy results from orientation of the fibers. This being a linear analysis more accurate results can be obtained by assigning nonlinear and anisotropic properties to PDL, for which further research is needed in this area.

\section{CLINICAL SIGNIFICANCE}

In clinical observation it might be expected that, for extrusive forces only tensile stresses are seen over the whole periodontal ligament. In our study, it was seen that when the extrusive force was applied using linear properties, the tensile stress was seen only at the apex, whereas compressive stresses were distributed along the cervical margin. Even during rotation there are stresses concentrated at the apex, hence due to the concentration of the compressive forces at the apex a clinician must avoid placing heavy stresses during tooth movement.

\section{REFERENCES}

1. Proffit WR, Fields HW, Ackerman JL, Sinclair PM, Thomas PM, Tulloch JF. Contemporary orthodontics. 2nd ed. Baltimore: Mosby-Year Book; 1993.

2. Storey E. Smith R. Force in orthodontics and its relation to tooth movement. Australian J Dentist 1952;56:11-18.

3. Reitan K. Effects of force magnitude and direction of tooth movement on different alveolar bone types. Angle Orthod 1964;34:244-255.

4. Lee K, Ryu Y, Park Y, Rudolph DJ. A study of holographic interferometry on the initial reaction of maxillofacial complex during protraction. Am J Orthod Dentofac Orthop 1997; 111:623-632.

5. Rudolph DJ, Willes MG, Sameshima GT. A finite element model of apical force distribution from orthodontic tooth movement. Angle Orthod 2001;71:127-131.

6. Nelson SJ, Ash MM Jr. Wheelers dental anatomy, physiology and occlusion. 7th ed, USA: WB Saunders Co 1993.

7. Dorow C. Numerische simulation und experimentelle Untersuchung der Zahnbewegung. [Dissertation]. Ulm: Universita; 2004.

8. Cobo J, Arguelles J, Puente M, Vijande M. Dentoalveolar stress from bodily tooth movement at different levels of bone loss. Am J Orthod Dentofacial Orthop 1996;110:256-262.

9. Lee B. Relationship between tooth movement rate and estimated pressure applied. J Dent Res 1965;44:1053.

10. Kamble, et al. Stress distribution pattern in a root of maxillary central incisor having various root morphologies. A finite element study. Angle Orthod 2012;82:799-805.

11. Koji oyama, et al. Effects of root morphology on stress distribution at the root apex. Eur J Orthod 2007;29:113-117. 